\title{
Manual de Laboratorio de Ondas y Partículas
}

ISBN (e) 8 978-958-8166-91-9

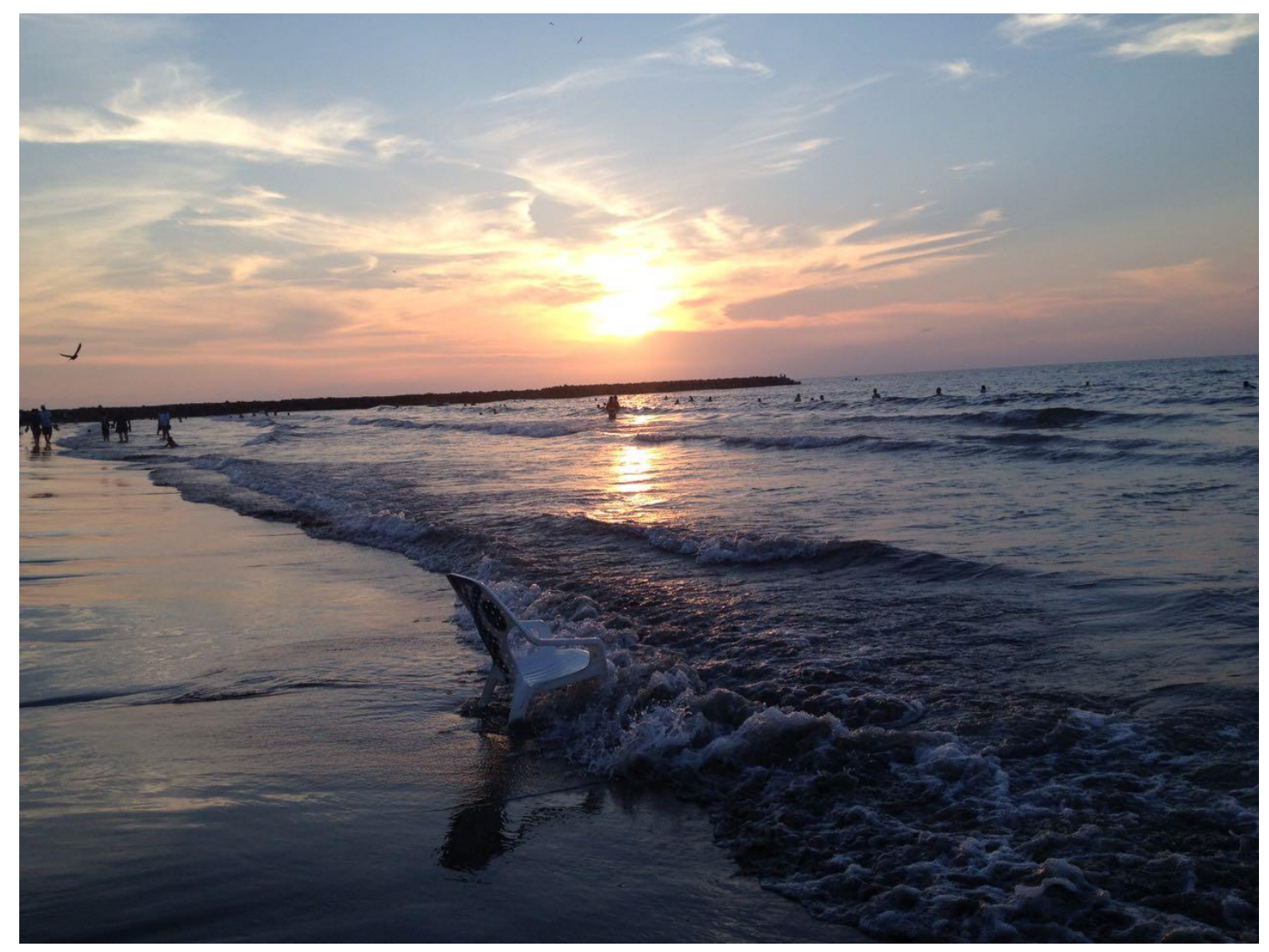

Ligia Beleño Montagut

Martha Lucía Barrera Pérez

Luis Alejandro Prada Martínez

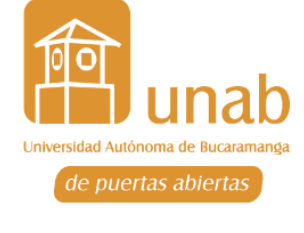




\title{
UNIVERSIDAD AUTÓNOMA DE BUCARAMANGA
}

Manual de Laboratorio de Ondas y Partículas

ISBN (e) 978-958-8166-91-9

\author{
ALBERTO MONTOYA PUYANA \\ Rector \\ EULALIA GARCÍA BELTRÁN \\ Vicerrectora Académica \\ GILBERTO RAMÍREZ VALBUENA \\ Vicerrector administrativo y financiero \\ NÓHORA ISABEL NÁJERA ESTEBAN \\ Directora \\ Departamento de Matemáticas y Ciencias Naturales \\ LIGIA BELEÑO MONTAGUT \\ Departamento de Matemáticas y Ciencias Naturales \\ MARTHA LUCÍA BARRERA PÉREZ \\ Departamento de Matemáticas y Ciencias Naturales \\ LUIS ALEJANDRO PRADA MARTÍNEZ \\ Autores \\ JOSE OSCAR MACHADO ROMERO \\ Corrección de Estilo. \\ PUBLICACIONES UNAB \\ Producción \\ Universidad Autónoma de Bucaramanga \\ Avenida $42 \mathrm{~N}^{\circ} 48-11$ \\ Bucaramanga, Colombia \\ www.unab.edu.co
}

Las opiniones contenidas en esta obra no vinculan a la Institución, sino que son exclusiva responsabilidad de los autores, dentro de los principios democráticos de la cátedra libre y la libertad de expresión consagrados en el artículo $3^{\circ}$ del Estatuto General de la Corporación Universidad Autónoma de Bucaramanga. 
Tabla de Contenido

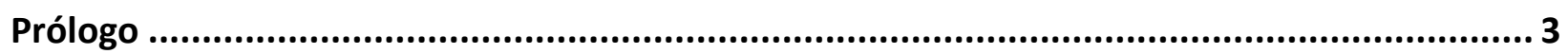

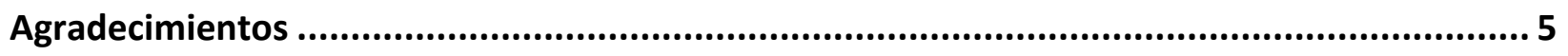

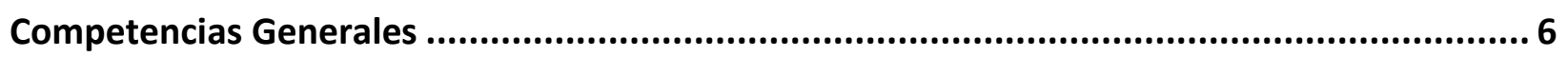

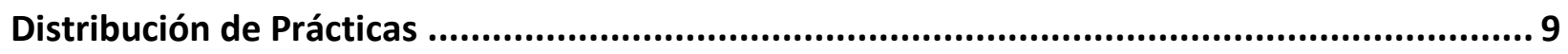

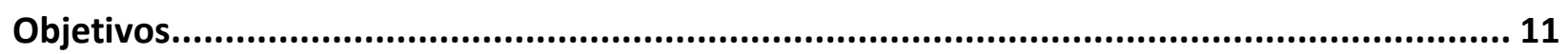

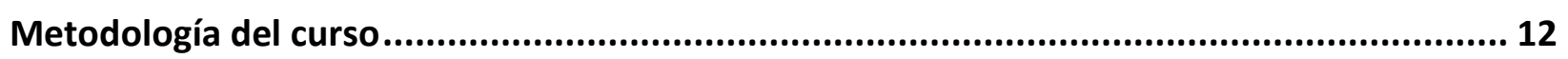

Sesión 1- Oscilador Masa-Resorte ............................................................................ 14

Sesión 2- Oscilador Forzado RLC Serie ................................................................. 19

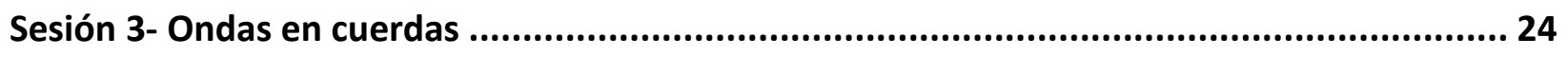

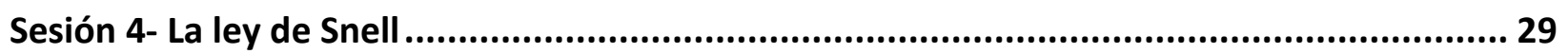

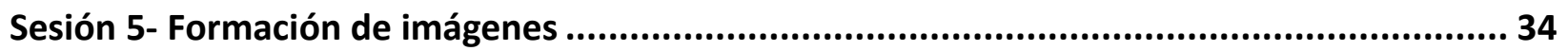

Sesión 6- Polarización de la luz y fotoelasticimetría.................................................. 39

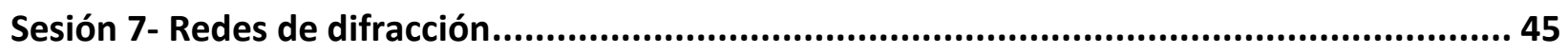




\section{Prólogo}

Este Manual de laboratorio es producto del análisis y trabajo continuo de los docentes de tiempo completo en la línea de física del departamento de Matemáticas y Ciencias Naturales. La finalidad del manual de laboratorio de Ondas y partículas es apoyar tanto al alumno como a otros docentes que imparten la misma asignatura. Mediante Observaciones y mediciones propuestas en las distintas sesiones podrán identificar las características de los movimientos ondulatorios y oscilatorios las cuales les permitirá abordar los temas de clase con mayor facilidad.

Se espera que el estudiante prepare con anticipación la fundamentación teórica que se sugiere en cada guía apoyándose en los libros, simulaciones y trabajos similares que le permita crear una representación previa acerca del trabajo que realizará en el laboratorio.

Cada una de las sesiones comprende aspectos importantes que serán abordados con más profundidad en la clase teórica, cumpliendo así con una función didáctica de manera paralela al curso de la teoría, ya que cada grupo de trabajo cuenta con el mismo material de apoyo y es orientado de manera permanente por el profesor del laboratorio acerca del fenómeno físico estudiado. Se inicia con un modelo de Oscilador Masa Resorte como tema básico para analizar las características cinemáticas y dinámicas de un movimiento armónico simple, en segundo lugar se analizan las características de un Oscilador Forzado, luego se estudian aplicaciones de la superposición de dos ondas (caso: Ondas en cuerdas), posteriormente las ondas electromagnéticas son estudiadas en laboratorios de: ley de Snell para estudiar el cambio de dirección de la luz al pasar de un medio transparente a otro, polarización para verificar las variaciones de intensidad con cambios en la dirección de dos polarizadores inicialmente alineados, formación de imágenes que permite evidenciar la imagen formada tanto en lentes convergentes como divergentes y, finalmente, redes de difracción para verificar las longitudes de ondas del espectro visible usando redes de difracción con diferente paso entre franjas de la red. 
Esperamos que el uso de este material por parte de los estudiantes les permita desarrollar sus habilidades y ampliar su visión como futuros ingenieros. Adicionalmente, las ideas y sugerencias resultado de la aplicación de este manual en las clases serán bien recibidas.

\section{Los autores}




\section{Agradecimientos}

Los autores agradecen a la Universidad Autónoma de Bucaramanga por el espacio académico de laboratorio el cual fortalece las habilidades de nuestros alumnos de ingeniería y a su vez representa un gran apoyo a los docentes en sus labores académicas.

Por otra parte se agradece a los compañeros y a los alumnos que con sus ideas y observaciones han participado de manera activa en este constante proceso de construcción.

De manera especial se valora el apoyo del Ingeniero Raúl Ortiz Rojas por su constante apoyo como auxiliar del laboratorio. 


\section{Competencias Generales}

\section{Respecto al trabajo en equipo}

- Propender por el logro de los objetivos del equipo de trabajo, con el fin de cumplir con los compromisos que requiere el desarrollo de la práctica experimental.

- Valorar las ideas y opiniones de los demás compañeros del equipo, para construir el análisis del experimento, a partir de las mismas.

- Colaborar activamente con sus compañeros del equipo con la propuesta de soluciones.

- Facilitar la comunicación, manteniendo relaciones productivas y respetuosas con los demás compañeros.

\section{Respecto a la iniciativa}

- Participar activamente, aportando ideas y estimulando a sus compañeros de grupo a trabajar de forma conjunta y proactiva.

- Tomar decisiones inmediatas cuando se detecte algún error en el procedimiento realizado, con el fin de reducir el riesgo de obtener resultados inconsistentes en el análisis del experimento.

- Analizar con profundidad las situaciones propuestas en las guías de laboratorio.

\section{Respecto a la flexibilidad}

- Adaptarse a cada situación que se presente durante el desarrollo de la experiencia de laboratorio.

- Propender por la tolerancia hacia los diversos puntos de vista de sus compañeros, con el fin de mantener la armonía y favorecer la toma de las mejores decisiones del grupo y así alcanzar las metas propuestas. 


\section{Respecto a la comunicación}

- Facilitar la comunicación con los demás miembros del grupo, socializando los resultados obtenidos durante la práctica.

- Escuchar activamente a sus compañeros, aportando la retroalimentación necesaria y analizando las participaciones de los demás, para el logro de los objetivos de la experiencia realizada.

\section{Respecto a la responsabilidad}

- Comprometerse con todas las actividades previas a la realización del experimento, así como durante el desarrollo del mismo.

- Estructurar el tiempo del desarrollo de la práctica con el fin de poder entregar los resultados del informe dentro del plazo definido en el reglamento del laboratorio de Física.

- Asumir con responsabilidad los errores cometidos por su equipo de trabajo, ya sea en la toma de mediciones, en el manejo de equipos y en la realización del informe, estableciendo con prontitud los correctivos necesarios para enmendarlos.

\section{Respecto al conocimiento}

- Expresar e interpretar conceptos y opiniones de forma oral y escrita, de acuerdo al contexto, con un buen manejo del vocabulario y aplicando correctamente las normas gramaticales del lenguaje. Análisis de un modelo específico al cual dará explicación con base en la toma de datos y análisis gráfico y de resultados.

- Desarrollar y aplicar el razonamiento matemático para la formulación de modelos que permitan explicar los fenómenos naturales estudiados en cada una de las prácticas de laboratorio. 
- Utilizar las herramientas tecnológicas para el tratamiento y el uso de la información obtenida en la toma de mediciones, con el fin de producir y presentar el análisis de los resultados en el reporte final de cada laboratorio. 


\section{Distribución de Prácticas}

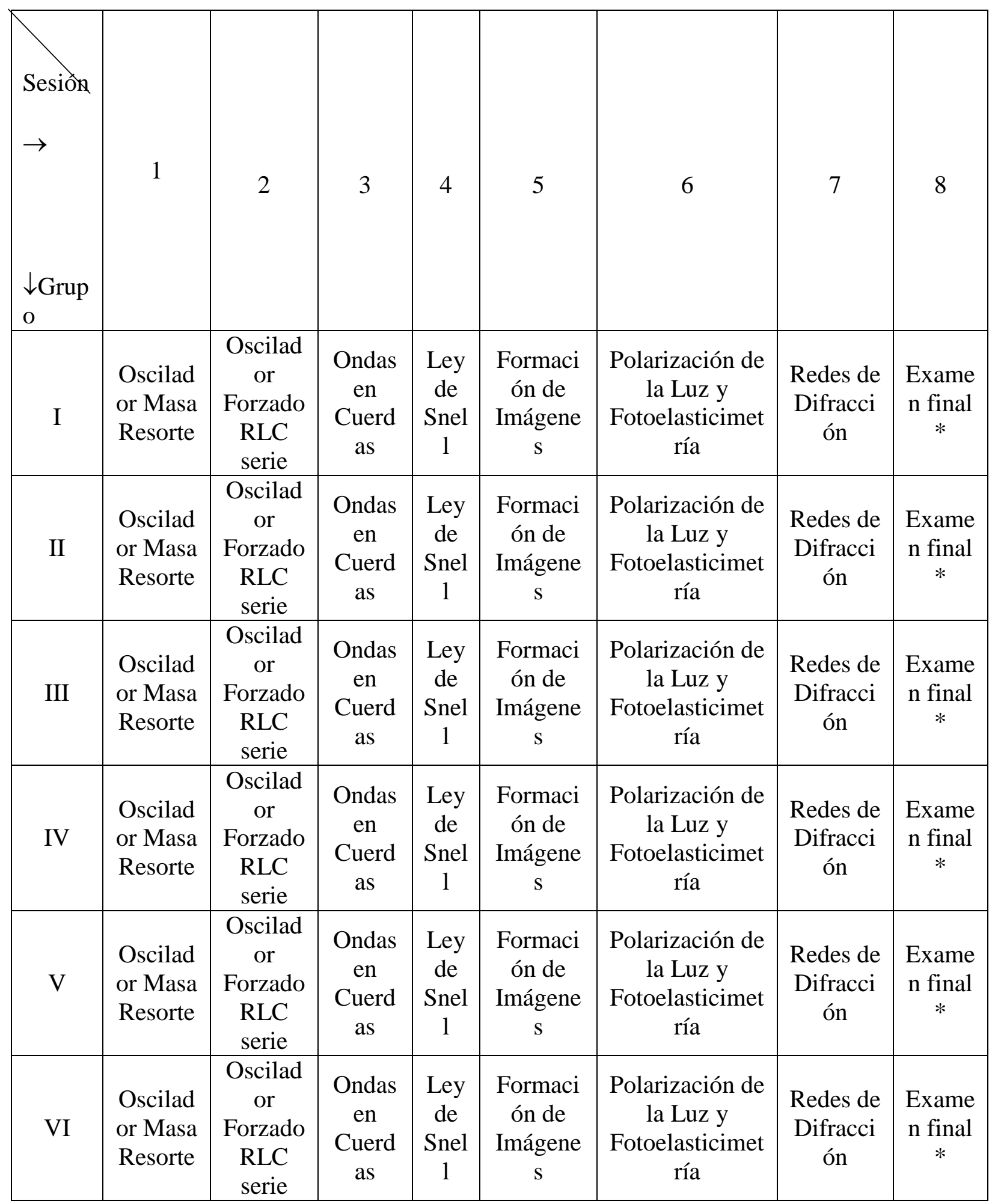




\begin{tabular}{|c|c|c|c|c|c|c|c|c|}
\hline \multirow{2}{*}{ VII } & $\begin{array}{c}\text { Oscilad } \\
\text { or Masa } \\
\text { Resorte }\end{array}$ & $\begin{array}{c}\text { Oscilad } \\
\text { or } \\
\text { Forzado } \\
\text { RLC } \\
\text { serie }\end{array}$ & $\begin{array}{c}\text { Ondas } \\
\text { en } \\
\text { Cuerd } \\
\text { as }\end{array}$ & $\begin{array}{c}\text { Ley } \\
\text { de } \\
\text { Snel } \\
1\end{array}$ & $\begin{array}{c}\text { Formaci } \\
\text { ón de } \\
\text { Imágene } \\
\text { s }\end{array}$ & $\begin{array}{c}\text { Polarización de } \\
\text { la Luz y } \\
\text { Fotoelasticimet } \\
\text { ría }\end{array}$ & $\begin{array}{c}\text { Redes de } \\
\text { Difracci } \\
\text { ón }\end{array}$ & $\begin{array}{c}\text { Exame } \\
\text { f final } \\
*\end{array}$ \\
\hline VIII & $\begin{array}{c}\text { Oscilad } \\
\text { or Masa } \\
\text { Resorte }\end{array}$ & $\begin{array}{c}\text { Oscilad } \\
\text { or } \\
\text { Forzado } \\
\text { RLC } \\
\text { serie }\end{array}$ & $\begin{array}{c}\text { Ondas } \\
\text { en } \\
\text { Cuerd } \\
\text { as }\end{array}$ & $\begin{array}{c}\text { Ley } \\
\text { de } \\
\text { Snel } \\
1\end{array}$ & $\begin{array}{c}\text { Formaci } \\
\text { ón de } \\
\text { Imágene } \\
\text { s }\end{array}$ & $\begin{array}{c}\text { Polarización de } \\
\text { la Luz y } \\
\text { Fotoelasticimet } \\
\text { ría }\end{array}$ & $\begin{array}{c}\text { Redes de } \\
\text { Difracci } \\
\text { ón }\end{array}$ & $\begin{array}{c}\text { Exame } \\
\text { n final } \\
*\end{array}$ \\
\hline
\end{tabular}




\section{Objetivos}

Comprobar los fenómenos oscilatorios y ondulatorios en modelos sencillos que les permita hacer una proyección hacia aplicaciones en la vida cotidiana.

Afianzar el uso del método científico en cuanto al procedimiento, análisis y conclusiones de los fenómenos físicos estudiados.

Fortalecer el trabajo en equipo, creando espacios de análisis y discusión que permitan establecer acuerdos y plantear ideas sólidas con el uso del lenguaje científico. 


\section{Metodología del curso}

Para el buen desempeño durante las prácticas del laboratorio de física se deben observar las siguientes recomendaciones:

- Durante la práctica, evite mantener dispositivos tales como: teléfonos celulares y demás objetos personales sobre el mesón de trabajo, estos pueden eventualmente convertirse en elementos que desvían su atención y la de sus compañeros. En su mesón de trabajo solamente debe permanecer su computador y sus herramientas de trabajo. Para ubicar su material que no hace parte de la práctica, el laboratorio dispone del gabinete inferior derecho del mesón de trabajo correspondiente al grupo. Se recomienda no perturbar el trabajo de los compañeros, evite visitar los mesones vecinos y las visitas de personas ajenas a la sesión del laboratorio.

- El laboratorio requiere de la lectura previa de los temas que se relacionan con la práctica correspondiente según indicaciones presentadas en este manual, como preparación para el quiz de entrada que se realizará en cada sesión.

- Para la toma de datos, los subgrupos se conformarán el primer día de clase y se asignará un número para identificar las prácticas que realizarán durante el semestre sin confusión alguna. La duración de cada experiencia es de 4 horas según las fechas estipuladas en el anexo 2 y consta de aproximadamente 2 horas para la toma de datos y 2 horas para la elaboración del informe.

- Al inicio de cada sesión, el auxiliar de laboratorio le hará entrega formal de los materiales de trabajo a cada grupo y recogerá un documento de identificación por mesa de trabajo. Al finalizar la práctica los estudiantes deberán hacer la entrega al auxiliar de los elementos suministrados y él a su vez les devolverá el documento.

- La práctica de laboratorio no tiene derecho a supletorio. En casos excepcionales se debe presentar una excusa, por escrito, dirigida al docente de laboratorio, quien tramitará dicha 
solicitud ante el equipo docente, para determinar la aceptación o no de dicha excusa. En caso de ser rechazada el estudiante tendrá nota de 0.0 (cero punto cero) en la sesión correspondiente y en caso de ser aceptada, se recuperará la experiencia en una única sesión programada por el equipo docente.

- El laboratorio aporta el $20 \%$ de la nota de la asignatura de Física: $10 \%$ para el primer corte (donde las prácticas de laboratorio serán el 7\% y los Quices 3\%); el 10\% restante (correspondiente a las demás prácticas serán el 3\%, y los Quices 2\% además de un examen final que aporta un 5\%) para el segundo corte, según las fechas estipuladas por la Universidad. 


\section{Sesión 1- Oscilador Masa-Resorte}

- Temas de consulta - Oscilador masa-resorte (Preparación previa a la práctica)

- Generalidades del Movimiento Oscilatorio.

- Movimiento Armónico Simple

- Ley de Hooke.

- Movimiento Amortiguado.

\section{Competencias}

Al finalizar la práctica el estudiante estará en capacidad de:

- Determinar experimentalmente la constante elástica de un resorte tanto mediante el método estático Ley de Hooke como usando el método dinámico.

- Interpretar el significado de la pendiente obtenida en las diferentes gráficas.

- Comparar ideas y opiniones para la toma de decisiones y planes respecto a la temática estudiada junto con sus compañeros de grupo.

\section{Materiales}

- Base o Soporte en V

- Varilla de $100 \mathrm{~cm}$.

- Soporte Rígido

- Resortes de diferentes constantes elásticas.

- Masas.

- Portamasas. 


\section{Procedimiento}

1. Con el material suministrado (Ver Figura 1a) realice el montaje de la Figura 1 b. Sujete diferentes pesos a un resorte y registre sus datos en una tabla. Los pesos están previamente calibrados a excepción del portapesas. Mida en cada caso el desplazamiento producido a partir de la posición de equilibrio.

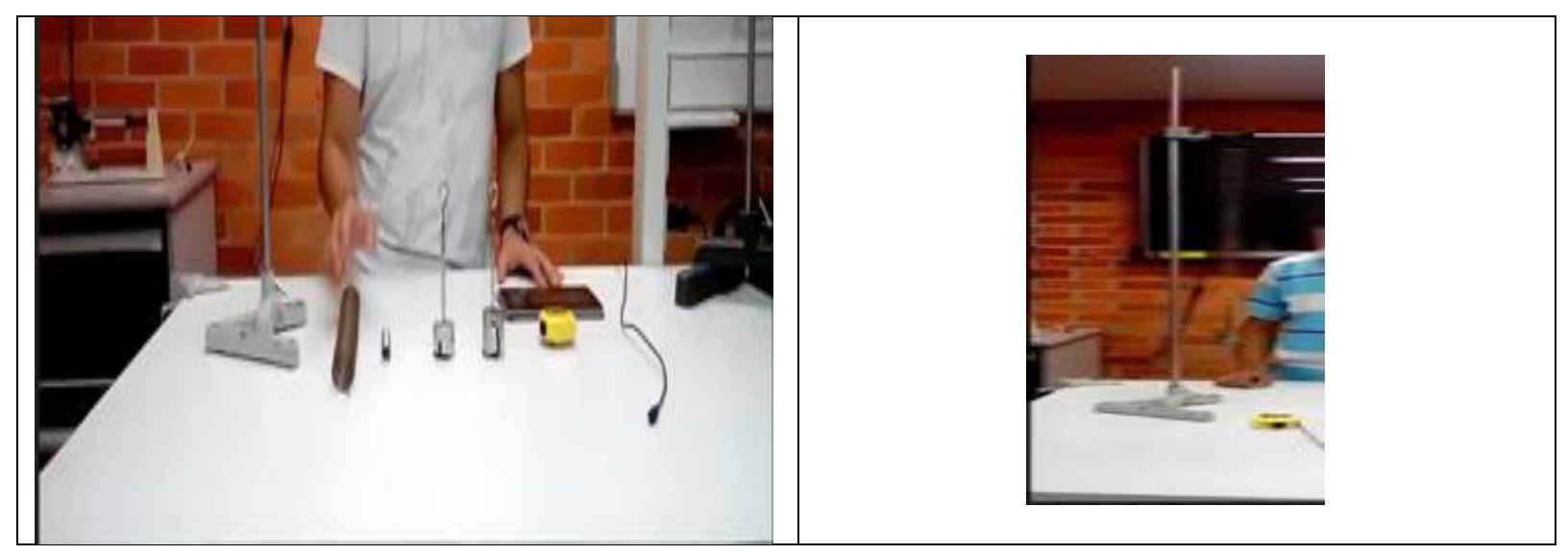

Figura 1. a) Materiales a utilizar b) Montaje Experimental Sistema masa-resorte

2. Relacione los datos obtenidos en tablas separadas para los distintos resortes sistemas acoplados.

3. Sujete en el resorte diferentes masas aumentando de acuerdo a las especificaciones del profesor y mida el tiempo que tarda el sistema en hacer $\mathrm{N}$ oscilaciones completas. Repita el procedimiento con la misma masa, por lo menos dos veces y reporte el promedio del tiempo para las $\mathrm{N}$ oscilaciones en la Tabla 1.

4. Realice el procedimiento desde el $1-3$ para otros resortes.

Tabla 1. Tabla de datos para el sistema Masa Resorte- Resorte 1

Valores sugeridos para el Resorte Grande: de 50 grs. en 50 grs. 


\begin{tabular}{|c|c|c|c|c|c|c|c|c|c|}
\hline \multirow{2}{*}{$N$} & \multirow{2}{*}{$\begin{array}{l}\text { Masa } \\
(\text { Kg })\end{array}$} & \multirow{2}{*}{$\begin{array}{l}\text { Fuerza } \\
W(N)\end{array}$} & \multirow{2}{*}{$\begin{array}{l}\text { Desplazamiento } \\
\text { (m) }\end{array}$} & \multicolumn{4}{|c|}{ Tiempo de n Oscilaciones (s) } & \multirow{2}{*}{$\begin{array}{l}\text { Periodo } \\
T(s)\end{array}$} & \multirow{2}{*}{$T^{2}\left(s^{2}\right)$} \\
\hline & & & & $\mathbf{t}_{1}$ & $\mathbf{t}_{2}$ & $\mathbf{t} 3$ & t Prom. & & \\
\hline 15 & & & & & & & & & \\
\hline 15 & & & & & & & & & \\
\hline 15 & & & & & & & & & \\
\hline 15 & & & & & & & & & \\
\hline 15 & & & & & & & & & \\
\hline 15 & & & & & & & & & \\
\hline 15 & & & & & & & & & \\
\hline
\end{tabular}

5. Realice el procedimiento desde el 1 - 3 para el sistema Masa-Resorte sumergido en el recipiente con agua y registre los datos en la Tabla2.

Tabla 2. Tabla de datos para el sistema Masa Resorte- Resorte pequeño con fricción Valores sugeridos para resorte pequeño en fricción con el Agua: de 50 grs. en 50 grs.

\begin{tabular}{|c|c|c|c|c|c|c|c|c|c|c|}
\hline \multirow[t]{2}{*}{$N$} & \multirow{2}{*}{$\begin{array}{l}\text { Masa } \\
(\mathrm{Kg})\end{array}$} & \multirow{2}{*}{$\begin{array}{l}\text { Fuerza } \\
W(N)\end{array}$} & \multirow{2}{*}{$\begin{array}{l}\text { Desplazamiento } \\
\text { (m) }\end{array}$} & \multicolumn{4}{|c|}{$\begin{array}{l}\text { Tiempo de } \quad n \\
\text { Oscilaciones }(s)\end{array}$} & \multirow{2}{*}{$\begin{array}{l}\text { Periodo } \\
T(s)\end{array}$} & \multirow{2}{*}{$\begin{array}{l}T^{2} \\
\left(s^{2}\right)\end{array}$} & \multirow{2}{*}{$\begin{array}{l}b \\
(N / m)\end{array}$} \\
\hline & & & & $t_{1}$ & $t_{2}$ & $t_{3}$ & tProm. & & & \\
\hline \multicolumn{11}{|l|}{15} \\
\hline \multicolumn{11}{|l|}{15} \\
\hline \multicolumn{11}{|c|}{15} \\
\hline \multicolumn{11}{|c|}{15} \\
\hline \multicolumn{11}{|l|}{15} \\
\hline \multicolumn{11}{|c|}{15} \\
\hline 15 & & & & & & & & & & \\
\hline
\end{tabular}

\section{Análisis}

Para cada uno de los resortes:

1. Graficar Fuerza, $\boldsymbol{W}$ vs Desplazamientos, $\Delta \boldsymbol{x}$.

2. Encontrar la constante $\boldsymbol{k}$ para cara resorte a partir de la pendiente de la recta de la gráfica anterior.

3. Graficar $\boldsymbol{T}^{2}$ vs. $\mathbf{m}$. 
4. Encontrar la constante $\boldsymbol{k}$ para cara resorte a partir de la pendiente de la recta de la gráfica anterior.

5. Acepte como teóricos los valores para las constantes de los resortes obtenidos en el punto 2 y calcule los respectivos porcentajes de error relativos a los valores encontrados en el punto 4.

6. Calcule el Factor de Amortiguamiento b, para cada masa en la tabla 2.

7. Exprese sus observaciones y conclusiones sobre los aspectos físicos de su experimento teniendo en cuenta: la teoría, el procedimiento, la tabla de datos, las gráficas y las fuentes de error.

8. Plantee tres aplicaciones relacionadas con sus estudios de ingeniería que se relacionen con el fenómeno físico estudiado en esta sesión. 


\section{Bibliografía}

Libro Digital: Volumen 1 y 2. Sears - Semansky, et al. Física universitaria con física moderna. Vol. 1. Editorial Pearson Education. Edición 13. Año 2013.

Link: www.ebooks7-24.com.aure.unab.edu.co/onlinepdfjs/view.aspx

Serway. R., et al., Física para ciencias e ingeniería. Vol. I y II. Editorial Cengage Learning. Edición 9. Año 2014.

Ohanian H., et al. Física para ingeniería y ciencias. Vol.1 y II Editorial Mc. Graw- HillInteramericana. Año 2009. 


\section{Sesión 2- Oscilador Forzado RLC Serie}

- Temas de consulta - Oscilador Forzado RLC Serie (Preparación previa a la práctica)

- Características de Movimiento Forzado.

- Circuitos RLC serie con Corriente Alterna.

- Resonancia en Circuitos RLC serie.

\section{Competencias}

Al finalizar la práctica el estudiante estará en capacidad de:

- Identificar las características de un circuito RLC forzado en serie para diferentes valores de resistencia, inductancia y capacitancia.

- Comparar ideas y opiniones para la toma de decisiones y planes respecto a la temática estudiada junto con sus compañeros de grupo.

\section{Materiales}

- Tablero de conexiones

- Resistencias de diferente valor Óhmico.

- Condensador.

- Bobina.

- Interruptor.

- conectores.

- Multímetro.

- Fuente de Corriente Alterna. 


\section{Procedimiento}

1. Conecte el circuito serie RLC con los valores de resistencia, inductancia y capacitancia suministrados de acuerdo a la Figura 1a. Para que el circuito se comporte como movimiento forzado, adicione también en serie una fuente de corriente alterna (Seleccione $5 \mathrm{~V}$ rms. o el valor indicado por el profesor) como se muestra en la Figura $\mathbf{1 b}$.

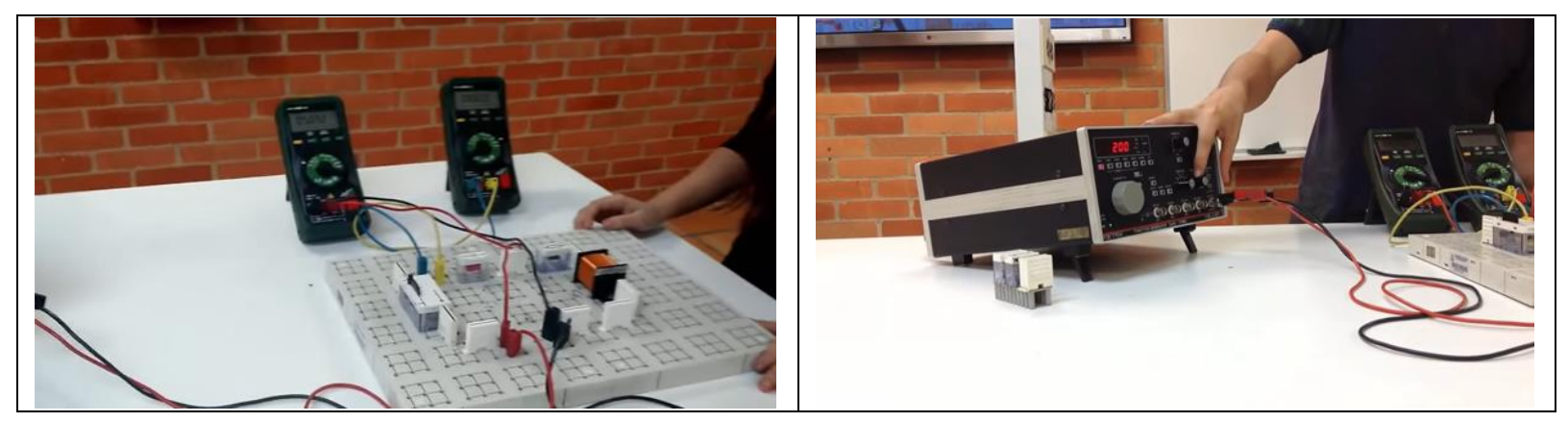

Figura 1. b) Montaje Experimental Sistema masa-resorte b) Generador de funciones en corriente alterna.

2. Para el valor de inductancia y capacitancia dados calcule el valor teórico de la frecuencia de resonancia del circuito.

3. Inicie la toma de datos con una frecuencia de $100 \mathrm{Ohm}$ y mida la corriente del circuito.

4. Continúe incrementando el valor de la frecuencia de manera que se tengan 6 valores antes y 10 valores después del valor de resonancia calculado en el punto 2.

5. Tenga en cuenta que debe llegar a una corriente similar a la medida con la frecuencia inicial, en caso contrario continúe haciendo mediciones hasta lograr este valor.

6. Repita el procedimiento anterior para otras dos resistencias. 
Tabla 1. Tabla de datos para la resistencia de $\mathbf{5 1 \Omega}$

Resistencia de $51 \Omega$

\begin{tabular}{|l|l|l|l|l|l|}
\hline FRECUENCIA & Corriente & Voltaje & Voltaje & Corriente & Teórica \\
$(\boldsymbol{H z})$ & Exp. (A) & VR (v) & Inductancia \\
\hline 200 & & & & L (H) \\
\hline 400 & & & & & \\
\hline 600 & & & & & \\
\hline 800 & & & & & \\
\hline 1000 & & & & & \\
\hline 1200 & & & & & \\
\hline 1400 & & & & & \\
\hline 1600 & & & & & \\
\hline 2000 & & & & & \\
\hline 2400 & & & & & \\
\hline 2800 & & & & & \\
\hline 3200 & & & & & \\
\hline 3600 & & & & & \\
\hline 4000 & & & & & \\
\hline 400 & & & & & \\
\hline 5200 & & & & & \\
\hline
\end{tabular}

\section{Análisis}

1. Realice la gráfica corriente Vs. Frecuencia para las tres resistencias utilizadas, calcule el ancho de banda y compare los resultados. 
2. A partir de su gráfico experimental obtenga el factor de calidad $Q M$ del circuito usando la expresión correspondiente, compare con el valor teórico de un sistema eléctrico. Indique sobre la gráfica el rango del ancho de banda para cada caso.

3. Calcule el desfase para la carga eléctrica y para la corriente eléctrica y plantee las correspondientes ecuaciones en función del tiempo.

4. Concluya respecto a los análisis y resultados del experimento.

5. Plantee tres aplicaciones relacionadas con sus estudios de ingeniería que se relacionen con el fenómeno físico estudiado en esta sesión. 


\section{Bibliografía}

Libro Digital: Volumen 1 y 2. Sears - Semansky, et al. Física universitaria con física moderna. Vol. 1. Editorial Pearson Education. Edición 13. Año 2013.

Link: www.ebooks7-24.com.aure.unab.edu.co/onlinepdfjs/view.aspx

Serway. R., et al., Física para ciencias e ingeniería. Vol. I y II. Editorial Cengage Learning. Edición 9. Año 2014.

Ohanian H., et al. Física para ingeniería y ciencias. Vol.1 y II Editorial Mc. Graw- HillInteramericana. Año 2009. 


\section{Sesión 3- Ondas en cuerdas}

- Temas de consulta - Ondas en cuerdas (Preparación previa a la práctica)

- Ondas Viajeras.

- Superposición de dos Movimientos Armónicos Simples.

- Ondas Estacionarias.

- Velocidad de propagación de una onda en una cuerda.

\section{Competencias}

Al finalizar la práctica el estudiante estará en capacidad de:

- Caracterizar experimentalmente las ondas estacionarias en cuerdas con sus dos extremos fijos.

- Describir el comportamiento de los armónicos en función de la frecuencia fundamental.

- Comparar ideas y opiniones para la toma de decisiones y planes respecto a la temática estudiada junto con sus compañeros de grupo.

\section{Materiales}

- Cuerdas de diferentes densidades lineales.

- Fuente de Vibración (Fuente acuática).

- Poleas Fijas.

- Base o Soporte en V.

- Varilla de $25 \mathrm{~cm}$.

- Mordaza múltiple.

- Gran variedad de Pesas. 


\section{Procedimiento}

De acuerdo con las Figuras $\mathbf{1} \boldsymbol{a} \boldsymbol{y} \mathbf{1 b}$ se dispone de un generador de funciones, una cuerda con una masa por unidad de longitud determinada, una polea y diferentes pesos. La tensión de la cuerda $\mathbf{T}$ depende del peso suspendido en uno de sus extremos. Un generador de funciones hace vibrar la cuerda a cierta frecuencia $\mathbf{f}$ y genera figuras estacionarias como se muestra en la Figura $\mathbf{1 b}$.

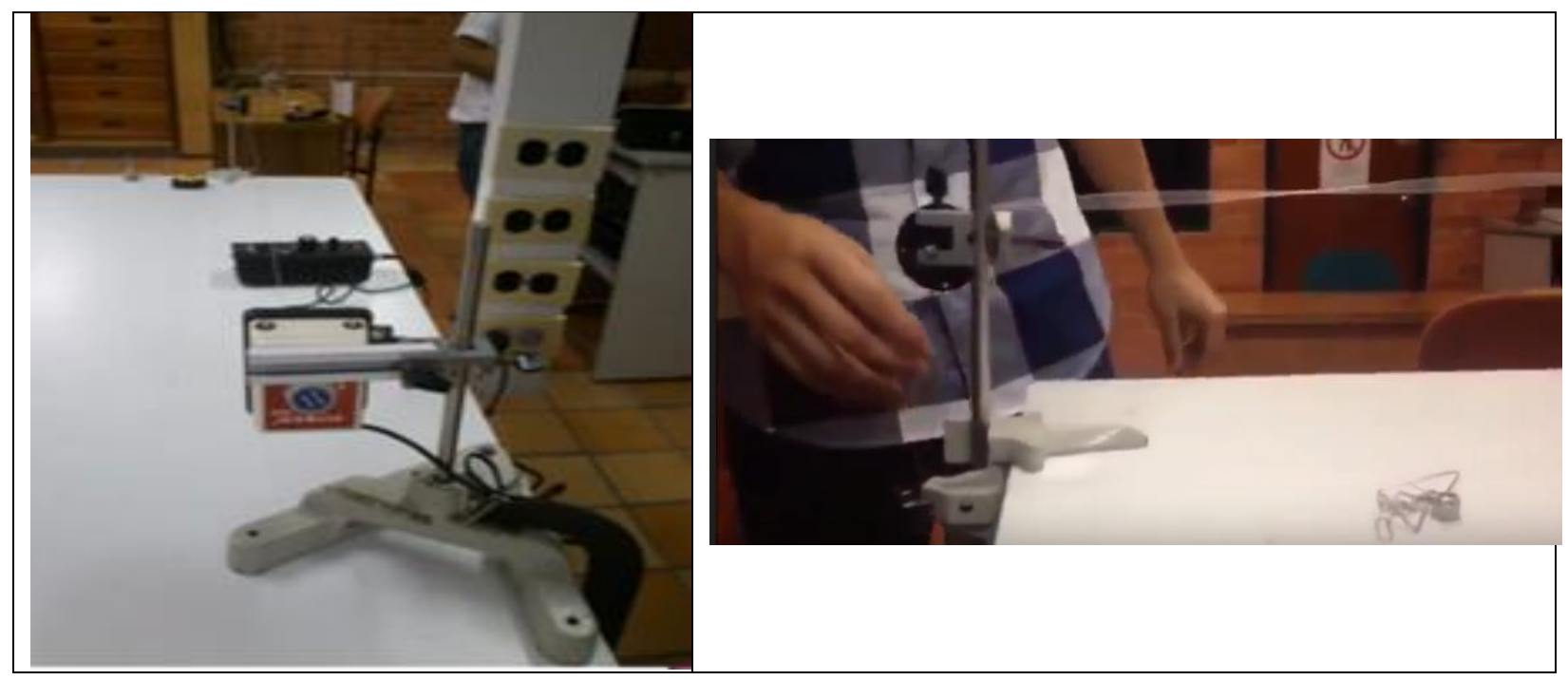

Figura 1. a) Montaje experimental b) Nodos y vientres en una cuerda

Recuerde: La longitud de la onda de cada modo está determinada por la longitud de la cuerda, la longitud L es igual a un número entero de veces de medias longitudes de onda.

1. Para un determinado valor de longitud de vibración $(\boldsymbol{L})$ y masa $(\boldsymbol{m})$ (indicados por el profesor) varíe ligeramente la longitud de la cuerda hasta obtener el primer vientre es decir la frecuencia fundamental de la cuerda. Tabule los datos en la tabla 1.

2. Para los mismos datos de tensión y la longitud del primer fundamental, disminuya la longitud de la cuerda hasta conseguir dos vientres y así sucesivamente hasta conseguir la cantidad de vientres establecidos por el profesor.

3. Para cada cuerda de densidad lineal diferente suspenda la masa indicada por el profesor y realice los dos pasos anteriores. 
4. Para una longitud fija suministrada por el profesor determine los valores de tensión para la misma cantidad de vientres representados en una tabla similar a la tabla 1 (Tenga en cuenta que usted puede modificar la tabla de acuerdo a la información que debe tabular).

5. Para los datos de la densidad lineal de las cuerdas $\boldsymbol{\mu}(\mathbf{k g} / \mathbf{m})$ suministrados por el profesor calcule la tensión y la velocidad de propagación de la onda.

$\mu$ cuerda gruesa $=$

$\boldsymbol{\mu}$ cuerda delgada $=$

$\boldsymbol{\mu}$ cuerda opcional $=$

Tabla 1. Tabla de datos para la cuerda 1

Cuerda 1 $\mu(\mathrm{kg} / \mathrm{m})$

\begin{tabular}{|l|l|l|l|l|}
\hline Longitud (m) & Peso (N) & $\begin{array}{l}\text { Velocidad de } \\
\text { Propagación } \\
(\mathrm{m} / \mathrm{s})\end{array}$ & $\begin{array}{l}\text { Número } \\
\text { Vientres }\end{array}$ & $\begin{array}{l}\text { Frecuencia } \\
(\mathrm{Hz})\end{array}$ \\
\hline & & & & \\
\hline & & & & \\
\hline & & & & \\
\hline & & & & \\
\hline & & & & \\
\hline & & & & \\
\hline & & & & \\
\hline
\end{tabular}

\section{Análisis}

1. Para cada valor de masa suspendida determiné la velocidad de propagación de la onda en la cuerda. 
2. En cada caso grafique velocidad ( $\boldsymbol{V})$ vs. $1 / \boldsymbol{n}$ (n es el número de vientres).

3. Analice las gráficas y compárelas. De acuerdo con el análisis dimensional, ¿Qué sentido físico tiene la pendiente? ¿Cuál es la ecuación que relaciona las variables que aparecen representadas en los ejes de la gráfica?

4. Evalúe el margen de error de la frecuencia a partir de cada gráfica.

5. Exprese sus observaciones y conclusiones sobre los aspectos físicos de su experimento teniendo en cuenta: la teoría, el procedimiento, la tabla de datos, las gráficas y las fuentes de error.

6. Plantee tres aplicaciones relacionadas con sus estudios de ingeniería que se relacionen con el fenómeno físico estudiado en esta sesión. 


\section{Bibliografía}

Libro Digital: Volumen 1 y 2. Sears - Semansky, et al. Física universitaria con física moderna. Vol. 1. Editorial Pearson Education. Edición 13. Año 2013.

Link: www.ebooks7-24.com.aure.unab.edu.co/onlinepdfjs/view.aspx

Serway. R., et al., Física para ciencias e ingeniería. Vol. I y II. Editorial Cengage Learning. Edición 9. Año 2014.

Ohanian H., et al. Física para ingeniería y ciencias. Vol.1 y II Editorial Mc. Graw- HillInteramericana. Año 2009. 


\section{Sesión 4- La ley de Snell}

- Temas de consulta - La Ley de Snell (Preparación previa a la práctica)

- Reflexión y Refracción

- Ley de Snell.

- Reflexión Interna Total (o ángulo crítico o límite).

- Ángulo de Brewster.

\section{Competencias}

Al finalizar la práctica el estudiante estará en capacidad de:

- Determinar experimentalmente el índice de refracción de diferentes tipos de líquidos transparentes a la luz y del vidrio a partir de la aplicación de la Ley de Snell.

- Reconocer el fenómeno de la reflexión total interna.

- Calcular el espesor de una lámina de caras paralelas mediante la aplicación de la Ley de Snell.

- Comparar ideas y opiniones para la toma de decisiones y planes respecto a la temática estudiada junto con sus compañeros de grupo.

\section{Materiales}

- Vidrio de 12 líneas.

- Cubetas.

- Alfileres.

- Plancha de Icopor.

- Líquidos transparentes a la luz (Alcohol, Glicerina, Petróleo, Agua).

\section{Procedimiento}

Tenga en cuenta que los gráficos de los rayo incidentes y refractados son un resultado experimental 
a partir de la observación en los distintos medios transparentes, por lo tanto adicionalmente a los datos, cálculos y gráficas de Excel debe entregar los gráficos obtenidos manualmente.

1. Ubique una lámina de vidrio sobre una hoja de papel milimetrada. Se recomienda orientar la hoja horizontalmente. Marque los bordes de la lámina de vidrio sobre el papel. Coloque un alfiler en el punto $\mathbf{O}$ (este punto será el punto de referencia en el alfiler verde en la figura 1a) y otro en el punto $\mathbf{P}$ (alfiler amarillo), los dos alfileres determinarán la recta $\mathbf{O P}$ que representa un haz de luz que viaja en el aire e incide sobre la lámina con ángulo $\theta_{i}$ respecto a la recta normal al borde del punto $\mathbf{O}$.

2. Observe a través de la lámina y haga coincidir la imagen del alfiler en el punto $\mathbf{O}$ con otro alfiler en el punto $\mathbf{P}_{\mathbf{r}}$ (alfiler rojo) que representa un haz refractado formando un ángulo $\theta_{\mathbf{r}}$ con la normal al borde de la lámina de vidrio en $\mathbf{O}$.

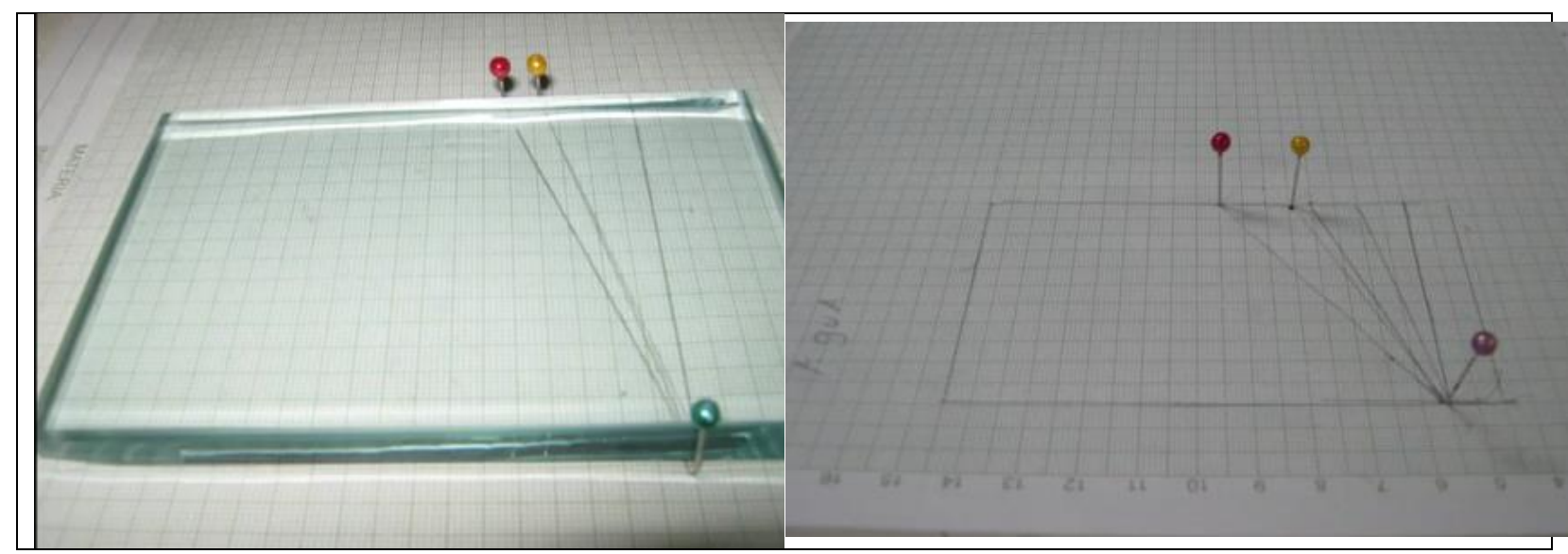

(a)

(b)

Figura 1. (a) Desviación de los Rayos respecto a la normal en el vidrio (b) Desviación de los Rayos quitando el vidrio

3. Retire el vidrio y mida lo ángulos de incidencia $\theta_{i}$ y de refracción $\boldsymbol{\theta}_{r}$. Repita la operación para cuatro posiciones del punto $\boldsymbol{P}$. Tabule sus datos.

4. Para los líquidos transparentes sugeridos por el profesor use la cubeta suministrada con un centímetro de altura del líquido correspondiente; considere que la cubeta se comporta de forma similar a la lámina de vidrio y repita los procedimientos 1 - 3 para cada caso. 
5. Para determinar experimentalmente el espesor de una lámina transparente de caras paralelas, como efectivamente lo son la lámina de vidrio y la cubeta con los diferentes líquidos, modificamos ligeramente el esquema de rayos de la Figura 1b. En la Figura 2 se muestra la desviación del rayo incidente $\boldsymbol{d}$ que permite calcular el espesor experimental de la lámina, el cual podrá posteriormente validar mediante la ecuación 1.

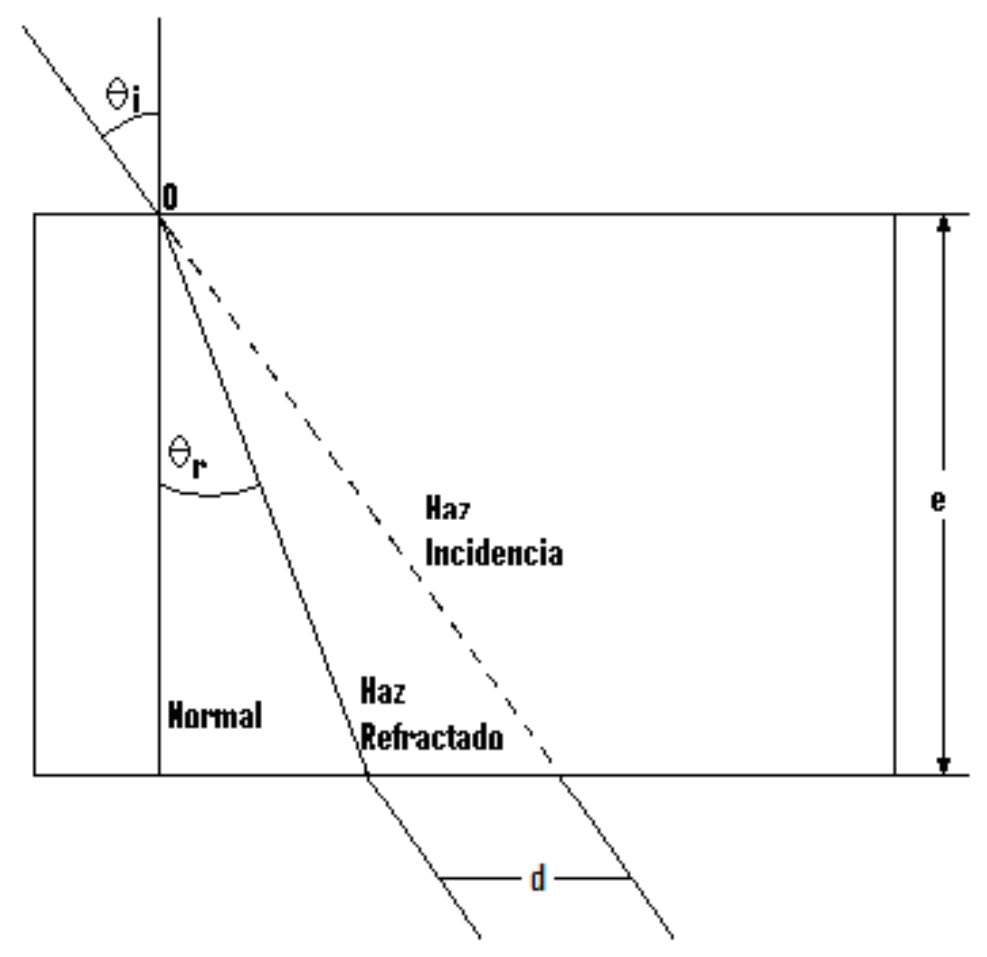

Figura 2. Medida del espesor de una lámina transparente de caras paralelas.

$$
e=\frac{d \cos \left(\theta_{r}\right)}{\operatorname{sen}\left(\theta_{i}-\theta_{r}\right)}
$$

6. Registre sus datos en la Tabla 1. 
Tabla 1. Tabla de datos para el vidrio

\begin{tabular}{|l|l|l|l|l|l|l|l|l|}
\hline $\begin{array}{l}\text { Ángulo de } \\
\text { Incidencia } \\
(\text { Grados })\end{array}$ & $\begin{array}{l}\text { Sen } \\
\left(\theta_{i}\right)\end{array}$ & $\begin{array}{l}\text { Ángulo de } \\
\text { Refracción } \\
\text { (Grados) }\end{array}$ & $\begin{array}{l}\text { Sen } \\
\left(\theta_{r}\right)\end{array}$ & $\begin{array}{l}\text { Índice de } \\
\text { Refracción }\end{array}$ & $\begin{array}{l}\% \\
\text { Error }\end{array}$ & $\begin{array}{l}\text { Desviación } \\
(\mathrm{cm} .)\end{array}$ & $\begin{array}{l}\text { Espesor } \\
(\mathrm{cm} .)\end{array}$ & $\begin{array}{l}\% \\
\text { Error }\end{array}$ \\
\hline & & & & & & & & \\
\hline & & & & & & & & \\
\hline & & & & & & & & \\
\hline & & & & & & & & \\
\hline
\end{tabular}

\section{Análisis}

1. Con base en los datos medidos registre en tablas similares a la tabla 1 los cálculos experimentales de los índices de refracción de la lámina de vidrio y de los líquidos utilizados.

2. Calcule el porcentaje de error entre los valores de los índices de refracción obtenidos en la experiencia con los valores reportados en la literatura.

3. Determine mediante la ecuación (1) el espesor de la lámina de vidrio y de la cubeta con líquidos. Calcule el porcentaje de error entre su medida real y su valor calculado.

4. Con base en los índices de refracción calculados para las diferentes sustancias determine el ángulo del ángulo límite $\theta_{c}$ y el ángulo de Brewster.

5. Exprese sus observaciones y conclusiones sobre los aspectos físicos de su experimento teniendo en cuenta: la teoría, el procedimiento, la tabla de datos, las gráficas y las fuentes de error.

6. Plantee tres aplicaciones relacionadas con sus estudios de ingeniería que se relacionen con el fenómeno físico estudiado en esta sesión. 


\section{Bibliografía}

Libro Digital: Volumen 1 y 2. Sears - Semansky, et al. Física universitaria con física moderna. Vol. 1. Editorial Pearson Education. Edición 13. Año 2013.

Link: www.ebooks7-24.com.aure.unab.edu.co/onlinepdfjs/view.aspx

Serway. R., et al., Física para ciencias e ingeniería. Vol. I y II. Editorial Cengage Learning. Edición 9. Año 2014.

Ohanian H., et al. Física para ingeniería y ciencias. Vol.1 y II Editorial Mc. Graw- HillInteramericana. Año 2009. 


\section{Sesión 5- Formación de imágenes}

\section{- Temas de consulta - Formación de Imágenes (Preparación previa a la práctica)}

- Refracción de la Luz.

- Características de las lentes delgadas.

- Sistemas formadores de imágenes.

\section{Competencias}

Al finalizar la práctica el estudiante estará en capacidad de:

- Verificar la ley de conjugación de la formación de imágenes en el dominio paraxial, mediante el cálculo de la distancia focal de lentes delgadas.

- Determinar las características de la imagen para sistemas conformados por una o más lentes.

- Verificar las relaciones de aumento para los sistemas anteriores.

- Comparar ideas y opiniones para la toma de decisiones y planes respecto a la temática estudiada junto con sus compañeros de grupo.

\section{MATERIALES}

- Banco Óptico.

- Fuente de luz blanca.

- Lentes de (50, 100, 175 o 200 mm)

- Imagen Objeto.

- Pantalla.

- Base o Soporte en V.

- Mordazas múltiples.

\section{Procedimiento}

1. Identifique el material dispuesto en el mesón, el cual será utilizado de esta práctica en adelante. Ver Figura 1a. 
2. Para cada una de las lentes suministradas en el laboratorio encuentre los planos conjugados imagen, correspondiente a diferentes planos objetos. Mida el tamaño del objeto, $\boldsymbol{o}$; tome 8 distancias objeto $\boldsymbol{X}_{\boldsymbol{o}}$ y encuentre su distancia imagen conjugada $\boldsymbol{X}_{\boldsymbol{i}}$ desplazando la pantalla hasta formar una imagen nítida. En cada caso mida el tamaño de la imagen $i$. En cada caso observe y describa la característica apreciada de la imagen. Ver Figura $\mathbf{1 b .}$
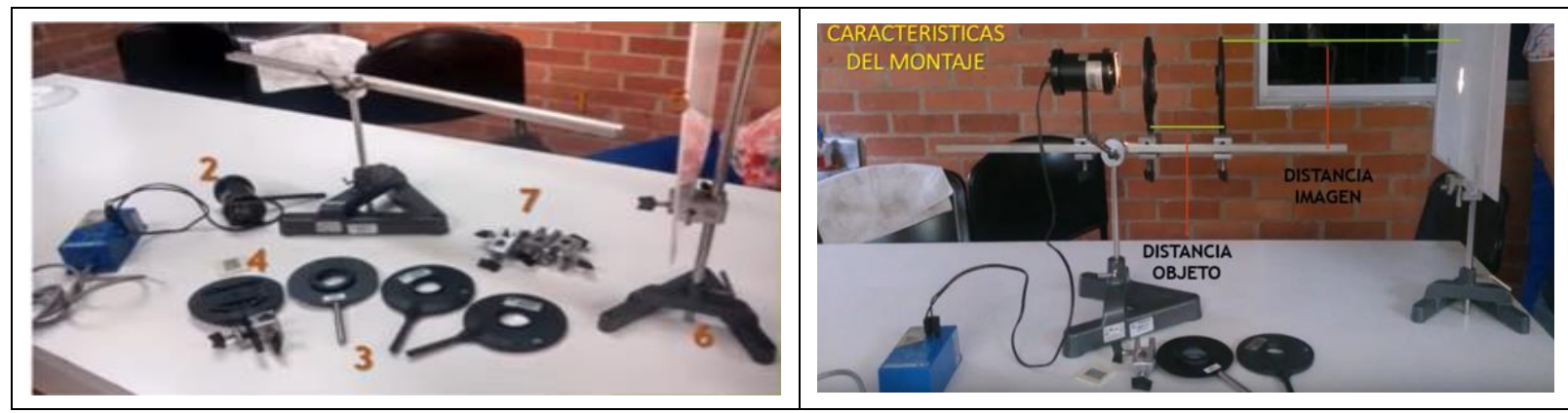

Figura 1. a) Materiales para el montaje. b) Montaje para el cálculo de la distancia focal de una lente convergente.

3. Registre sus datos de acuerdo a la tabla correspondiente a cada lente según la tabla 1 sugerida.

Tabla 1. Tabla de datos para la lente convergente de $50 \mathrm{~mm}$

\begin{tabular}{|l|l|l|l|l|l|l|}
\hline $\begin{array}{l}\text { Distancia objeto } \\
\text { (cm) Distancia imagen } \\
\text { características sus }\end{array}$ & $\begin{array}{l}\text { Tamaño de la imagen (cm) y } \\
\text { (cm) y sustancia } \\
\text { características }\end{array}$ & $\begin{array}{l}\text { Tálculo del aumento } \\
\text { cánal (cm) } \\
\text { focal }\end{array}$ \\
\hline & & & & & & \\
\hline & & & & & & \\
\hline & & & & & & \\
\hline & & & & & & \\
\hline & & & & & & \\
\hline
\end{tabular}

4. Nos proponemos determinar la distancia focal de las lentes empleadas en el punto anterior mediante el procedimiento de Bessel. Se fija la distancia $\boldsymbol{a}$ entre el plano objeto y la pantalla. Se determinan dos posiciones de la lente, respecto al objeto, para las cuales se forma la imagen del objeto en la pantalla. Mida la distancia $s$ entre las dos posiciones. Ver Figura 2. 


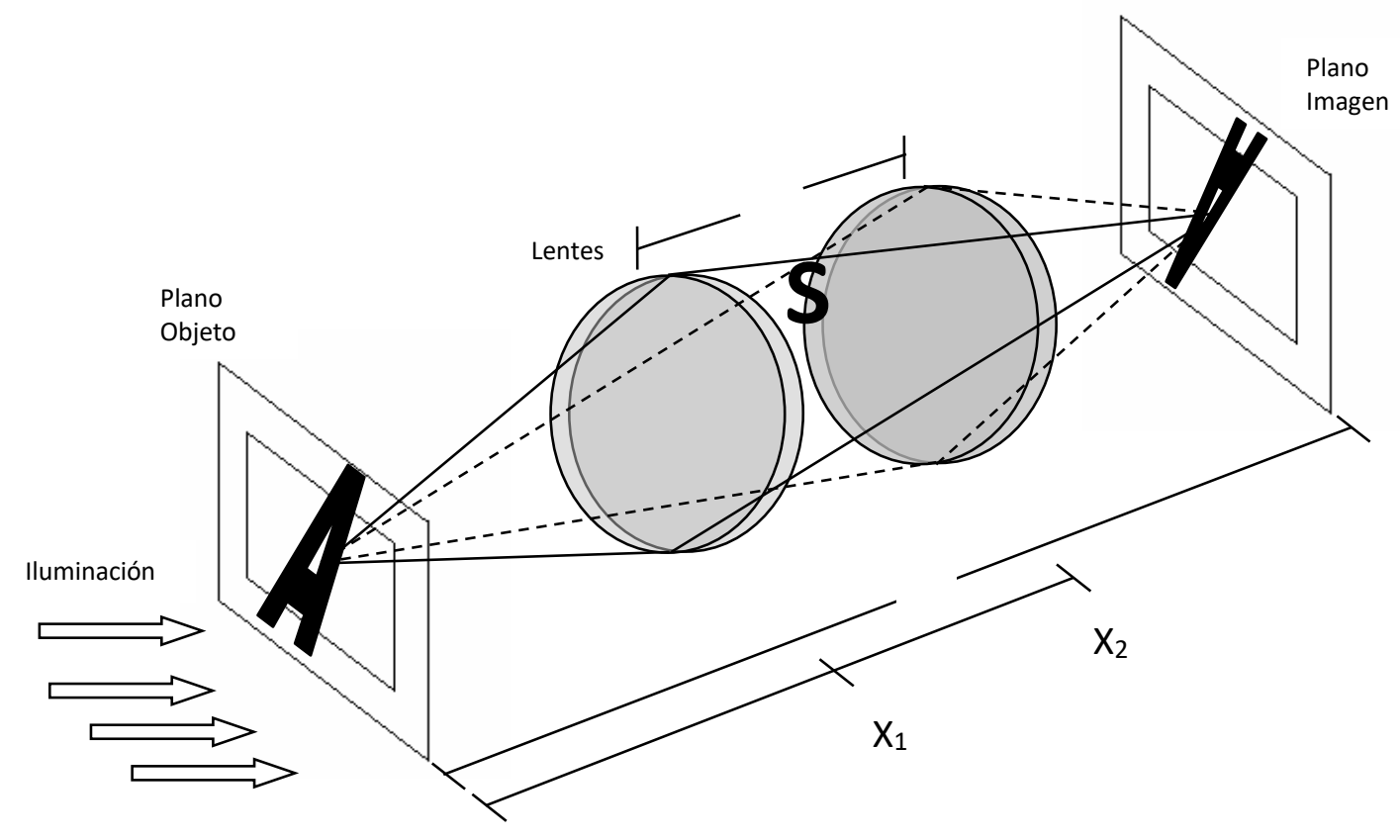

Figura 2. Cálculo de la distancia focal de una lente mediante el procedimiento de Bessel.

5. Registre sus datos en la Tabla 5 .

Tabla 5. Tabla de datos para la lente divergente

DISTANCIA FOCAL SEGÚN BESSEL

\begin{tabular}{|l|l|l|l|l|l|l|}
\hline \multicolumn{2}{|l|}{ Posición 1 (m) } & \multicolumn{2}{|l|}{ Posición 2 (m) } & $S=\left[X_{2}-X_{1}\right]$ & $\begin{array}{l}\text { Distancia } \\
\text { total a }(m)\end{array}$ \\
\hline $\begin{array}{l}\text { Distancia } \\
\text { objeto } X_{1}\end{array}$ & $\begin{array}{l}\text { Distancia } \\
\text { imagen } X_{1}\end{array}$ & $\begin{array}{l}\text { Distancia } \\
\text { objeto } X_{2}\end{array}$ & $\begin{array}{l}\text { Distancia } \\
\text { imagen } X_{2}\end{array}$ & $S=\left[X_{2}-X_{1}\right]$ & $S=\left[X_{2}^{\prime}-X_{1}^{\prime}\right]$ & \\
\hline & \multicolumn{2}{|l|}{} & & \\
\hline
\end{tabular}

\section{Análisis}

1. De acuerdo a los datos de la tabla 1 grafique el recíproco de la distancia objeto, $\frac{1}{X_{0}}$ contra el recíproco de la distancia imagen $\frac{1}{X_{1}}$; interprete físicamente los cortes de la recta con los ejes. 
2. Determine la distancia focal $\boldsymbol{f}$ a partir de la gráfica anterior. Tome como valor aceptado la distancia focal proporcionada por el fabricante y calcule el porcentaje de error respectivo al valor obtenido en la fábrica.

3. Calcule la distancia focal a partir de la ley de conjugación para la formación de imágenes y realice la gráfica a escala con los tres rayos principales para los tres casos típicos de posición del objeto respecto a la lente (más allá del foco, en el foco y entre el vértice y el foco):

$$
\frac{1}{X_{0}}+\frac{1}{X_{1}}=\frac{1}{f}
$$

4. Determine el valor de la distancia focal mediante la fórmula de Bessel y los datos registrados en la tabla 2.

$$
f=\frac{(a-s)(a+s)}{4 a}
$$

Compare con las distancias focales suministradas por el fabricante, determinando el porcentaje de error entre estos valores respecto a las calculadas mediante la fórmula anterior.

5. Determine el valor de la posición de la imagen final tanto experimental como matemáticamente combinando dos lentes convergentes.

6. De acuerdo a la teoría, los objetivos, el procedimiento, los datos obtenidos y calculados y sus gráficas, observe, analice y concluya sin perder de vista los aspectos físicos de este experimento.

7. Plantee tres aplicaciones relacionadas con sus estudios de ingeniería que se relacionen con el fenómeno físico estudiado en esta sesión. 


\section{Bibliografía}

Libro Digital: Volumen 1 y 2. Sears - Semansky, et al. Física universitaria con física moderna. Vol. 1. Editorial Pearson Education. Edición 13. Año 2013.

Link: www.ebooks7-24.com.aure.unab.edu.co/onlinepdfjs/view.aspx

Serway. R., et al., Física para ciencias e ingeniería. Vol. I y II. Editorial Cengage Learning. Edición 9. Año 2014.

Ohanian H., et al. Física para ingeniería y ciencias. Vol.1 y II Editorial Mc. Graw- HillInteramericana. Año 2009. 


\section{Sesión 6- Polarización de la luz y fotoelasticimetría}

- Temas de consulta - Polarización de la Luz y fotoelasticimetría (Preparación previa a la práctica)

- Clases de Polarización.

- Polariscopio.

- Ley de Malus.

- Ángulo de Brewster.

- Sustancias Birrefringentes

- Actividad Óptica, líneas isoclínicas e isocromáticas

- Materiales Isotrópicos y Anisotrópicos.

- Aplicaciones industriales de la Polarización

\section{Competencias}

- Analizar el fenómeno de polarización mediante la observación y medición de la intensidad de la luz a la salida de un polariscopio simple, para comprender diferentes aplicaciones en la industria.

- Comparar ideas y opiniones para la toma de decisiones y planes respecto a la temática estudiada junto con sus compañeros de grupo.

\section{Materiales}

- Fuente de Luz blanca.

- Analizador.

- Polarizador.

- Fotómetro o Fotorresistencia.

- Multímetro. 
- Fuente de corriente continua.

- Materiales Fotoelásticos o Birrefringentes.

- Lente convergente.

- Base o Soporte en V.

- Banco Óptico.

- Mordazas Múltiples.

\section{Procedimiento}

Identifique los polarizadores dentro del material dispuesto en el mesón, el cual será utilizado en esta práctica (ver Figura 1a), y realice el montaje del polariscopio según la Figura $\mathbf{1 b}$.

\section{Verificación del Teorema de Malus}

1. Observe a través del polariscopio lineal los efectos ópticos en función del ángulo del material estudiado, girando el indicador amarillo del analizador (ver Figura 1a), cada $10^{\circ}$ grados desde $-90^{\circ}$ a $0^{\circ}$ y de $0^{\circ}$ a $90^{\circ}$ grados y usando un fotómetro, mida las variaciones de la intensidad luminosa transmitida en función del ángulo entre los dos polarizadores. Para ello, mantenga constante la distancia fuente - detector y rote el analizador hasta observar que la intensidad transmitida varíe.

2. Tabule sus datos según la Tabla 1.

Figura 1. Polariscopio

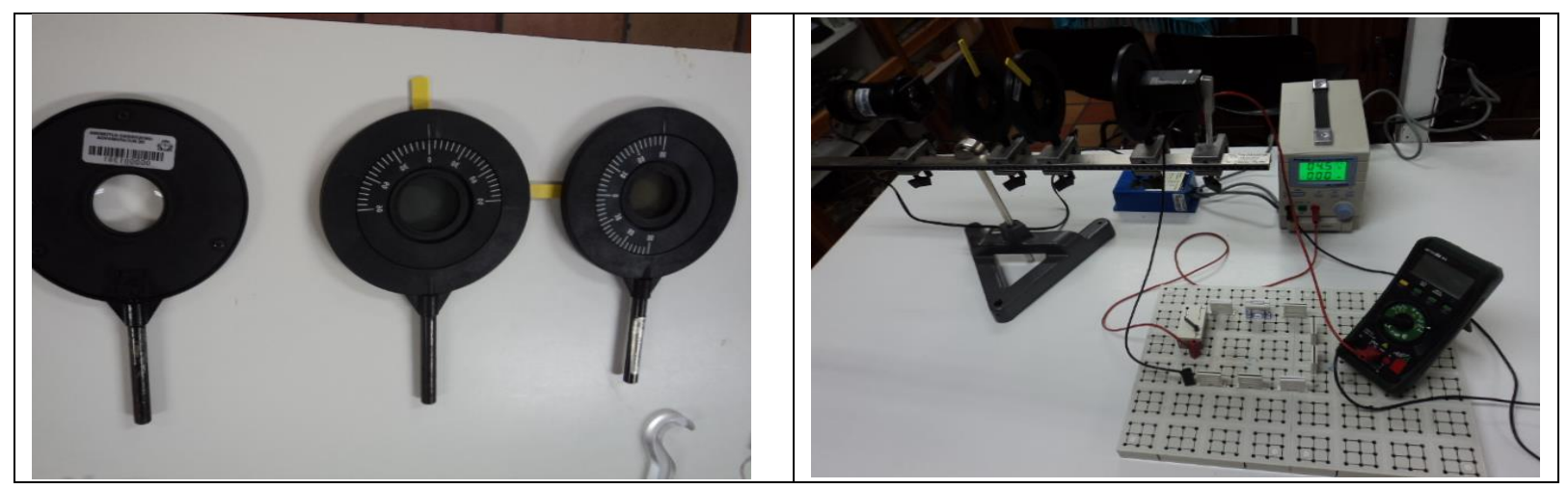


Figura 1. a) Materiales para el montaje b) Montaje de un polariscopio

Tabla 1. Tabla de datos para el análisis con luz blanca sin filtro

\begin{tabular}{|c|c|c|c|c|}
\hline $\begin{array}{l}\text { Intensidad de } \\
\text { Entrada }(m A)\end{array}$ & $\begin{array}{l}\text { Intensidad de } \\
\text { Entrada } \\
\text { Experimental } \\
(m A)\end{array}$ & $\operatorname{Angulo}(\theta)$ & $\begin{array}{l}\text { Intensidad de } \\
\text { Salida }(m A)\end{array}$ & $\begin{array}{lr}\text { Intensidad } & \text { de } \\
\text { Entrada } & / \\
\text { Intensidad de } \\
\text { Salida }\end{array}$ \\
\hline & & $-90^{\circ}$ & & \\
\hline & & $-80^{\circ}$ & & \\
\hline & & $-70^{\circ}$ & & \\
\hline & & $-60^{\circ}$ & & \\
\hline & & $-50^{\circ}$ & & \\
\hline & & $-40^{\circ}$ & & \\
\hline & & $-30^{\circ}$ & & \\
\hline & & $-20^{\circ}$ & & \\
\hline & & $-10^{\circ}$ & & \\
\hline & & 0 & & \\
\hline & & 10 & & \\
\hline & & 20 & & \\
\hline & & 30 & & \\
\hline & & 40 & & \\
\hline & & 50 & & \\
\hline & & 60 & & \\
\hline & & 70 & & \\
\hline & & 80 & & \\
\hline & & 90 & & \\
\hline
\end{tabular}

Observación del estado de polarización de materiales fotoelásticos en función de esfuerzos mecánicos

3. Utilizando el montaje óptico de la figura 2 observe a través de un polariscopio lineal varios materiales. 


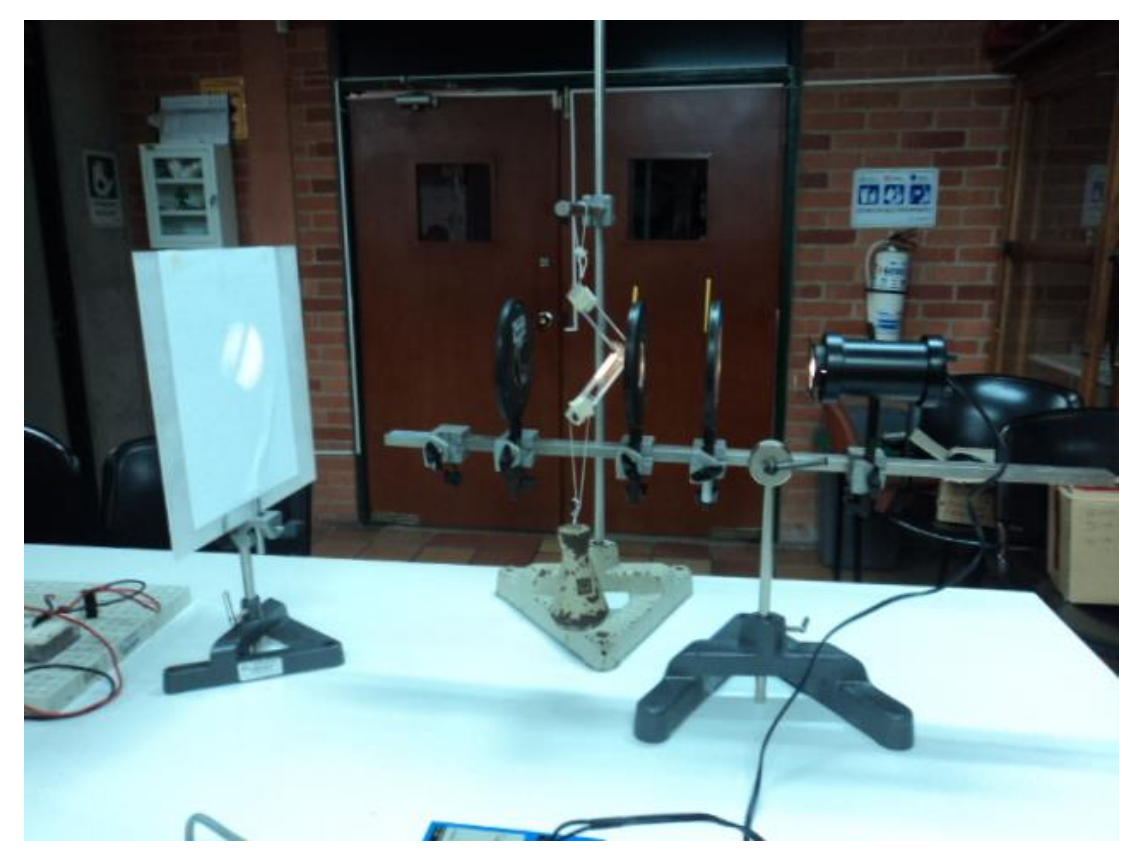

4. Explique los efectos en función del ángulo del material estudiado (a $0^{\circ}$ grados y a $90^{\circ}$ grados) entre el polarizador y el analizador,

5. Observar la polarización de los materiales fotoelásticos con peso y sin peso utilizando diferentes filtros. Realice para cada modelo cuatro gráficas observadas (con peso y sin peso usando polarizadores cruzados, con peso y sin peso usando polarizadores paralelos).

6. Escriba las observaciones con cada uno de los modelos suministrados por el profesor (describa respecto a las líneas isoclínicas e isocromáticas).

\section{Análisis}

\section{Verificación del Teorema de Malus}

1. Según la tabla 1 Represente gráficamente la intensidad de la luz transmitida I :(con filtro y sin filtro).

En función de $(\theta)$

En función de $\operatorname{Cos}^{2}(\theta)$ 
2. Explique a partir de estos gráficos si la luz polarizada linealmente obedece a la Ley de Malus.

3. Analice y justifique las gráficas de acuerdo a la ley de Malus.

Observación del estado de polarización de materiales fotoelásticos en función de esfuerzos mecánicos

1. Describa los cambios observados en los materiales fotoelásticos al aumentar su peso, al cambiar de $0^{\circ}$ grados a $90^{\circ}$ grados el analizador y al cambiar el filtro.

2. Realice un modelo simple mostrando cómo se distribuyen las tensiones en el interior de un objeto en relación a esfuerzos externos. Explique cómo cambian las líneas isoclínicas e isocromáticas con polarizadores cruzados y paralelos.

3. Exprese sus observaciones y conclusiones sobre los aspectos físicos de su experimento teniendo en cuenta: la teoría, el procedimiento, la tabla de datos, las gráficas y las fuentes de error.

4. Plantee tres aplicaciones relacionadas con sus estudios de ingeniería que se relacionen con el fenómeno físico estudiado en esta sesión. 


\section{Bibliografía}

Libro Digital: Volumen 1 y 2. Sears - Semansky, et al. Física universitaria con física moderna. Vol. 1. Editorial Pearson Education. Edición 13. Año 2013.

Link: www.ebooks7-24.com.aure.unab.edu.co/onlinepdfjs/view.aspx

Serway. R., et al., Física para ciencias e ingeniería. Vol. I y II. Editorial Cengage Learning. Edición 9. Año 2014.

Ohanian H., et al. Física para ingeniería y ciencias. Vol.1 y II Editorial Mc. Graw- HillInteramericana. Año 2009. 


\section{Sesión 7- Redes de difracción}

- Temas de consulta - Redes de Difracción (Preparación previa a la práctica)

- Redes de Difracción.

- Espectros de emisión de una lámpara de incandescencia.

- Interferencia y Difracción Interferencia.

\section{Competencias}

Al finalizar la práctica el estudiante estará en capacidad de:

- Verificar la teoría de la difracción utilizando diferentes redes de difracción iluminadas por luz blanca.

- Comparar ideas y opiniones para la toma de decisiones y planes respecto a la temática estudiada junto con sus compañeros de grupo.

\section{Materiales}

- Lámpara de luz blanca.

- Lente convergente.

- Diafragma.

- Lente convergente de $50 \mathrm{~mm}$.

- Red de difracción de 600 o 300 líneas por milímetro.

- Banco óptico.

\section{Procedimiento}

1. Realice el montaje del espectroscopio mostrado en la Figura 1a. Se trata de un espectroscopio basada en una red de difracción que permite estudiar las componentes emitidas por las fuentes 
S (ver Figura 1 b), mantenga los elementos alineados en sus centros, es decir, paralelos al eje óptico del sistema.

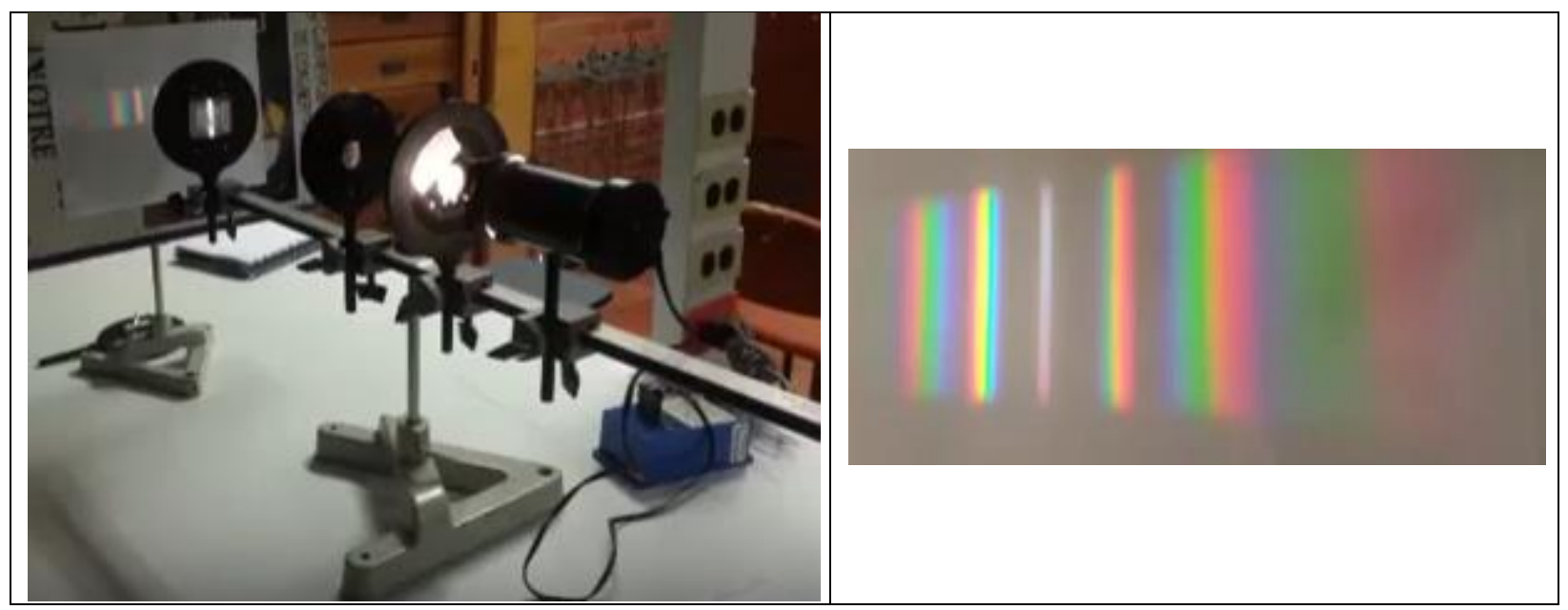

Figura 1. a) Montaje general del experimento b) Espectro de luz blanca observado en la pantalla

2. Coloque en la posición de S la fuente de radiación correspondiente al láser, lámpara de mercurio o lámpara incandescente. Coloque una lente convergente y desplácela con respecto a la fuente, obteniendo un haz de luz uniforme según el esquema de la Figura 2a. Mediante el diafragma seleccione una posición del frente de onda uniforme e ilumine la red de difracción. Observe la distribución de la radiación visible en la pantalla.

3. Identifique los órdenes de difracción que aparecen en la pantalla. Mida la distancia $\boldsymbol{L}$ desde la pantalla, la red de difracción y la separación de las líneas espectrales en cada orden, respecto al orden cero de Intensidad, (el orden cero es la radiación que no es desviada y se mantiene paralela al eje óptico). Estas dos mediciones permiten determinar el seno del ángulo $\boldsymbol{\theta}, \boldsymbol{F i g u r a} \mathbf{2 b}$. 


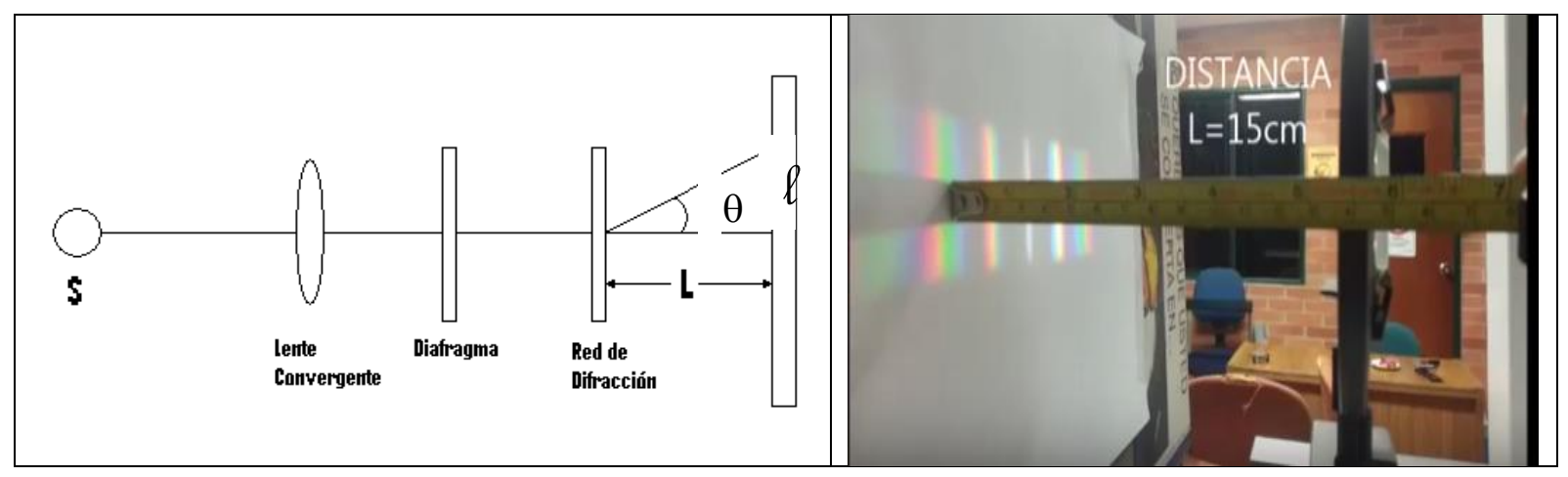

Figura 2. a) Esquema general para la medida del ángulo $\theta$ b) Medida experimental para las líneas en diferentes órdenes de difracción.

4. Tabule sus registros en la Tabla 1. Recuerde $\boldsymbol{L}$ es la distancia de la pantalla de observación red de difracción, $\boldsymbol{d}$ es el periodo espacial de la red, es decir, el inverso del paso de la red; 1 es la distancia del orden central a una línea espectral de longitud de onda $\lambda$ que pertenece al orden $n=0,+1,+2, \ldots$ según corresponda en su toma de datos. Plantee un cuadro similar para tomar datos con otra red de difracción y con un láser He-Ne

Tabla 1. Tabla de datos para el análisis con luz blanca - red de 600 líneas/mm - primer orden Primer Orden (600 líneas/mm)

\begin{tabular}{|l|l|l|l|}
\hline$L=$ & $d=$ \\
\hline $\begin{array}{l}\text { Orden } \\
\text { Difracción, } n\end{array}$ & $\begin{array}{l}\text { Distancia de la red a } \\
\text { la pantalla, } l(m)\end{array}$ & $\operatorname{sen}(\theta)=\frac{\lambda}{\sqrt{\left(\lambda^{2}+L^{2}\right)}}$ & $\begin{array}{l}\text { Longitud de onda } \\
\text { experimental } \lambda(\mathrm{m})\end{array}$ \\
\hline & & & \\
\hline & & & \\
\hline & & & \\
\hline & & & \\
\hline & & & \\
\hline
\end{tabular}


Tabla 2. Tabla de datos teóricos para las longitudes de onda del visible

\begin{tabular}{|l|l|l|}
\hline \multicolumn{2}{|l|}{ Fuente } & $\begin{array}{l}\text { Algunas Líneas Espectrales } \\
\text { en el visible (nm) }\end{array}$ \\
\hline \multirow{3}{*}{$\begin{array}{l}\text { Lámpara Incandescente } \\
(\text { Luz Blanca) }\end{array}$} & Lámpara de Mercurio, Hg & 405.8 Violeta \\
\cline { 3 - 3 } \begin{tabular}{l}
$\lambda=\frac{d(\operatorname{sen}(\theta))}{n}(1)$ \\
\cline { 3 - 3 }
\end{tabular} & & 545.8 Azul \\
\cline { 2 - 3 } & Láser He-Ne & 579.8 Amarillo \\
\hline
\end{tabular}

\section{Análisis}

1. A partir de la ecuación 1 complete la tabla 1.

2. Identifique las líneas que tienen igual longitud de onda en el caso de la toma de datos con la lámpara incandescente y en el caso del láser y describa otras características similares.

3. Realice la gráfica $\lambda$ (experimental) Vs. $\operatorname{Sen} \theta$ para los datos de la lámpara incandescente e interprete la ecuación obtenida.

4. Calcule el porcentaje de error para cada longitud de onda emitida comparando los datos experimentales con los datos suministrados en la siguiente tabla. Nota: recuerde evaluar en el punto medio de cada longitud de onda.

5. ¿Se puede plantear una relación respecto al número de líneas en la red de difracción y la separación observada en los distintos órdenes?

6. Exprese sus observaciones y conclusiones sobre los aspectos físicos de su experimento teniendo en cuenta: la teoría, el procedimiento, la tabla de datos, las gráficas y las fuentes de error.

7. Plantee tres aplicaciones relacionadas con sus estudios de ingeniería que se relacionen con el fenómeno físico estudiado en esta sesión. 


\section{Bibliografía}

Libro Digital: Volumen 1 y 2. Sears - Semansky, et al. Física universitaria con física moderna. Vol. 1. Editorial Pearson Education. Edición 13. Año 2013.

Link: www.ebooks7-24.com.aure.unab.edu.co/onlinepdfjs/view.aspx

Serway. R., et al., Física para ciencias e ingeniería. Vol. I y II. Editorial Cengage Learning. Edición 9. Año 2014.

Ohanian H., et al. Física para ingeniería y ciencias. Vol.1 y II Editorial Mc. Graw- HillInteramericana. Año 2009. 